\title{
Evidence of high production levels of thermostable dextrinizing and saccharogenic amylases by Aspergillus niveus
}

\author{
Tony Marcio da Silva ${ }^{1}$, Alexandre Maller ${ }^{2}$, Simone de Carvalho Peixoto-Nogueira ${ }^{2}$, \\ Michele Michelin ${ }^{1}$, João Atílio Jorge ${ }^{1}$ and Maria de Lourdes Teixeira de Moraes Polizeli ${ }^{1 *}$ \\ ${ }^{1}$ Departamento de Biologia - FFCLRP - Universidade de São Paulo, Ribeirão Preto, Brazil. \\ ${ }^{2}$ Departamento de Bioquímica e Imunologia - FMRP - Universidade de São Paulo, Ribeirão Preto, Brazil.
}

Accepted 8 February, 2013

\begin{abstract}
The aim of this work was to analyze the effect of several nutritional and environmental parameters on amylase production by a novel, isolated from the thermotolerant filamentous fungus Aspergillus niveus. This strain produced high levels of amylolytic activity in Khanna liquid medium supplemented with commercial starch, initial $\mathrm{pH} \mathrm{6.5,} \mathrm{under} \mathrm{static} \mathrm{conditions} \mathrm{for} 72 \mathrm{~h}$. Among the tested carbon sources, milled corn, oatmeal, soluble potato starch and maisena were the best inducers of enzymatic secretion $(220,180,170$ and $150 \mathrm{U} / \mathrm{mL})$, respectively. The main products of hydrolysis analyzed by thin layer chromatography were glucose, maltose and traces of maltooligosaccharides, suggesting the presence of $\alpha$-amylase and glucoamylase activities in the crude extract. The optimal pH were 4.5 and 5.5 and the optimum temperature was $65^{\circ} \mathrm{C}$. The enzymes were fully stable up to $1 \mathrm{~h}$ at $55^{\circ} \mathrm{C}$. It was possible to verify the presence of three bands with amylolytic activity in non-denaturing polyacrylamide gel electrophoresis (PAGE). These aspects and other properties suggested that the amylases produced by $A$. niveus might be suitable for biotechnological applications.
\end{abstract}

Key words: Starch, a-amylase, glucoamylase, Aspergillus niveus, submerged fermentation, thermostability.

\section{INTRODUCTION}

Amylases are hydrolytic enzymes produced by plants for the assimilation of starch present in some types of roots; animals for the digestion of starch present in food (Aiyer, 2005) and by many prokaryotic (Salahuddin et al., 2011) and eukaryotic microorganisms that use starch as carbon source (Peixoto et al., 2003, Reddy et al., 2003). aAmylase (E.C. 3.2.1.1 or 1, 4- $\alpha$-D-glucan glucanohydrolase) is the key enzyme in the metabolism of a wide variety of living organisms, which use starch as carbon and energy sources. This enzyme randomly cleaves the internal $\alpha-1,4-$ glucosidic linkages of starch,

* Corresponding author. E-mail: polizeli@ffclrp.usp.br. Tel: +55 16 36024680. Fax: +55 1636024886.

Abbreviation: PAGE, Polyacrylamide gel electrophoresis. glycogen, and related polysaccharides to produce oligosaccharides of different sizes (Reddy et al., 2003; Bhanja et al., 2007). a-Amylases are the most important enzymes because of their potential application in industrial process, such as in the fermentation, textiles, pharmaceuticals, detergent, brewing, baking, paper and food industries (Gupta et al., 2003, Bhanja et al., 2007, Salahuddin et al., 2011). a-Amylase is essential through the starch processing and plays an important role in the liquefaction of starch and its subsequent saccharification, where larger carbohydrate chains are hydrolyzed and converted into smaller carbohydrates (Chaplin and Bucke, 1990; Baks et al., 2006).

Glucoamylase hydrolyzes $\alpha-1,4$ and $\alpha-1,6$ linkages of starch and related polymers to produce glucose as the sole end-product. Glucoamylase also hydrolyzes other starch-related oligo- and polysaccharides, and shows a preference for the hydrolysis of maltooligosaccharides of 
at least six residues (Sukara and Doelle, 1989; Cereia et al., 2006). One of most important applications of glucoamylases is the production of high glucose syrups from starch, and these enzymes are also used in the production of ethanol and in the baking and brewing industries (Imai et al., 1994).

The current work constitutes the first study on concomitant production of $\alpha$-amylase and glucoamylase by Aspergillus niveus, a fungus considered as an excellent producer of other enzymes such as xylanase (Peixoto-Nogueira et al., 2008; Betini et al., 2009), amylases (Silva et al., 2010) and pectinases (Maller et al., 2011). Then, the aim of this work was to describe the production of amylases by $A$. niveus on submerged fermentation supplemented with different carbon sources and the characterization of end-products of hydrolysis on the soluble starch.

\section{MATERIALS AND METHODS}

\section{Microorganism and growth conditions}

A. niveus was isolated from the fruit, Mangifera indica and identified at Universidade Federal de Pernambuco (Recife/Pernambuco, Brazil). The organism was maintained in PDA medium with mineral oil, under refrigeration. Approximately $10^{7}$ spores $/ \mathrm{mL}$ from 3-day-old cultures were inoculated into $125 \mathrm{~mL}$ Erlenmeyer flasks containing $25 \mathrm{~mL}$ of different media as Adams (Adams, 1990), Czapek (Wiseman, 1975), SR (Rizzatti et al., 2001) and Khanna (Khanna et al., 1995) supplemented with $1 \%$ starch (w/v).

\section{Cultivation conditions}

The composition of Adams, Czapek, SR and Khanna media (Adams, 1990; Wiseman, 1975; Rizzatti et al., 2001; Khanna et al., 1995), respectively was evaluated for amylase production using cultivation under stirring or stationary conditions, a $72 \mathrm{~h}$ period, at $40^{\circ} \mathrm{C}$. Amylase production was standardized in Khanna medium and time-course was carried out up to six days, at $40^{\circ} \mathrm{C}$. In order to study the effect of $\mathrm{pH}$ and temperature, the fungus was cultivated in Khanna medium at different $\mathrm{pHs}$ (range of 4.5 to 7.5 ) and temperature $\left(25\right.$ to $\left.50^{\circ} \mathrm{C}\right)$. The effects of physical conditions on the fungus incubation (static $x$ stirred) were tested incubating the fungus intercalating on static and stirred conditions for $144 \mathrm{~h}$, at $40^{\circ} \mathrm{C}$.

\section{Preparation of crude enzyme and growth quantification}

Filtrates were obtained by filtration through filter paper in a Buchner funnel. The filtrates were dialyzed against $0.1 \mathrm{M}$ sodium acetate buffer, $\mathrm{pH} 5.0$, at $4^{\circ} \mathrm{C}$, overnight. After that, the samples were used as a source of crude extracellular amylolytic activity, while mycelia were dried in stove until constant weight for the quantification of the dry biomass.

\section{Enzymatic assay}

The amylase activities were determined by measuring the production of reducing sugar using 3,5-dinitrosalicylic acid (DNS) as described by Miller (1959). The assay was carried out at $65^{\circ} \mathrm{C}$ using
$1.0 \%$ starch solution in $0.1 \mathrm{M}$ sodium acetate buffer, $\mathrm{pH}$ 5.0. An enzyme unit was defined as the amount of released reducing sugar at an initial rate of $1 \mu \mathrm{mol} \mathrm{min}^{-1}$ at $65^{\circ} \mathrm{C}$. In addition, the enzyme activity was measured according to Cereia et al. (2006), using soluble starch as substrate, in which the amount of glucose released was estimated by peroxidase/glucose oxidase. Protein was determined by Lowry method (Lowry et al., 1951) using bovine serum albumin as standard.

\section{Effect of different carbon sources on amylases production}

The effect of different carbon sources was evaluated using $1 \%$ soluble starch, milled corn, oat meal, maisena, amylopectin, maltose, rice straw, raffinose, wheat bran, sugar cane bagasse, lactose, sucrose, corn cob, arabinose and without any carbon source. The temperature, cultivation time and $\mathrm{pH}$ of cultivation were $40^{\circ} \mathrm{C}, 72 \mathrm{~h}$ and 6.5 , respectively. The enzymatic assay was followed as described in the previous item. The cultures with soluble starch and without carbon source were used as control.

\section{Enzymatic characterization}

The optimum $\mathrm{pH}$ was determined at $65^{\circ} \mathrm{C}$ using citrate-phosphate buffer ( $\mathrm{pH}$ range 3.0 to 8.0 ). The $\mathrm{pH}$ stability was determined at $30^{\circ} \mathrm{C}$, for $2 \mathrm{~h}$, after pre-incubation of the diluted enzyme in citrate phosphate buffer at different $\mathrm{pH}$ values ( $\mathrm{pH}$ range 3.0 to 8.0 ). The thermostability was determined by measuring the residual activity after the incubation of the diluted enzyme in the absence of substrate at 50 to $70^{\circ} \mathrm{C}$ in $0.1 \mathrm{M}$ sodium acetate buffer at $\mathrm{pH} 5.0$, for $6 \mathrm{~h}$.

\section{Identification of hydrolysis products}

The hydrolysis products of amylase activity on soluble starch (1\%) as substrate were analyzed using thin-layer chromatography (TLC). The mobile phase was composed by butanol/ethanol/water (5:3:2 $\mathrm{v} / \mathrm{v} / \mathrm{v})$. Sugars were determined with $0.2 \%$ orcinol in a methanolsulfuric acid (9:1 v/v) mixture (Aquino et al., 2003). Glucose, maltose, maltotriose, maltotetraose and maltopentaose at $1 \%$ were used as standards.

\section{Amylolytic activities in polyacrylamide gel electrophoresis (PAGE)}

Non-denaturing polyacrylamide gel electrophoresis (PAGE) was performed in 5 to $10 \%$ gels according to Davis method (Davis, 1964). Two identical samples were applied in the gel. After the electrophoresis procedure, this gel was vertically cut into two parts, obtaining two lanes with identical migration of proteins: $(A)$ the gel was incubated with $0.5 \mathrm{M}$ acetate buffer, $\mathrm{pH} 5.0$ during 30 min and immediately immersed in $1 \%(\mathrm{w} / \mathrm{v})$ potato starch where it was maintained during $20 \mathrm{~min}$. The amylolytic activity was determined by incubation of the gel with a mixture of solutions of $0.3 \% \mathrm{KI}$ and $0.15 \% \mathrm{I}_{2}$ until the appearance of the bands of amylolytic activity; (B) the other part of the gel was sliced into several segments, which were macerated in the presence of $0.1 \mathrm{M}$ sodium acetate buffer, $\mathrm{pH}$ 5.0 and incubated in the presence of $1 \%$ starch for $2 \mathrm{~h}$. The products formed were quantified by DNS (Miller, 1959) and by GOD (glucose oxidase kit).

\section{Reproducibility of the results}

All data were statistically analyzed. 

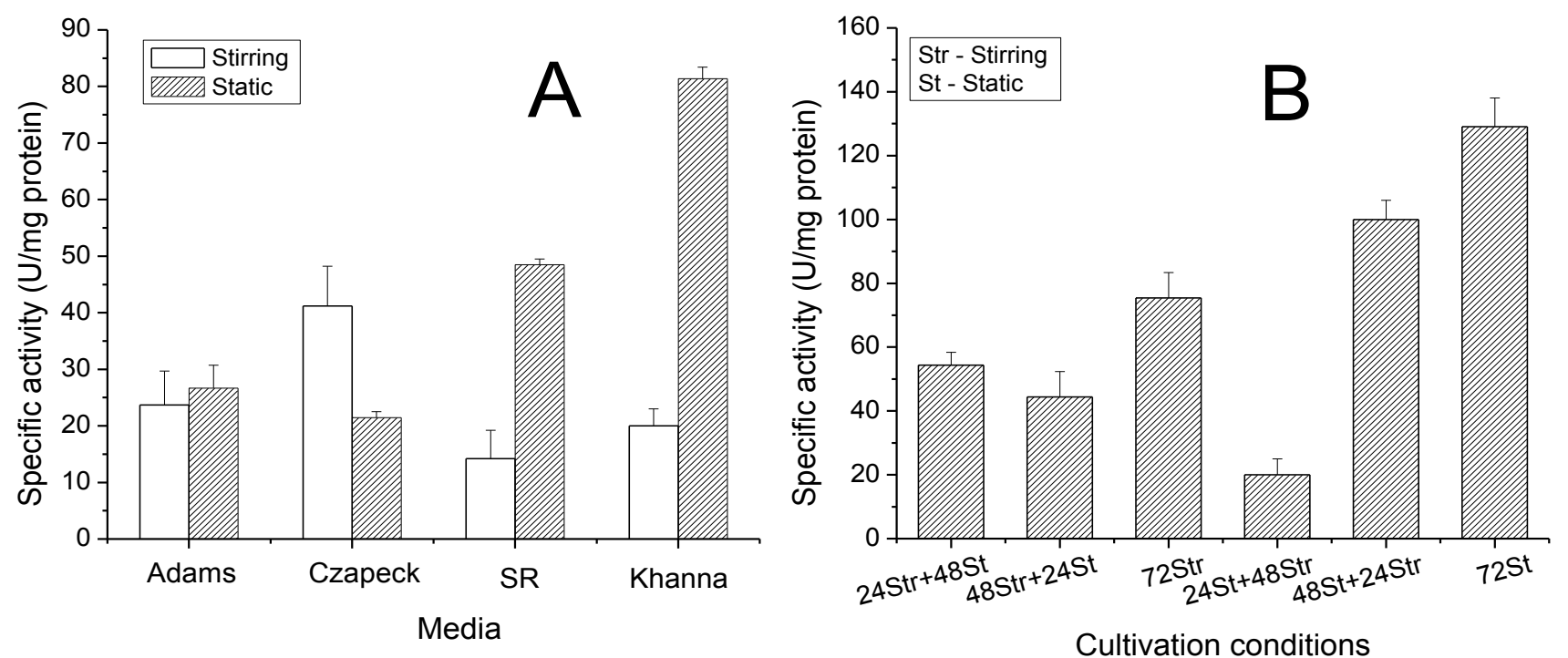

Figure 1. (A) Effect of different media and (B) physical parameters in amylase production. White bars represent stirred conditions (Str) and hachured bars represent static conditions (St).

\section{RESULTS AND DISCUSSION}

\section{Evaluation of different cultivation media and combinations of physical methods to increase the enzymatic production}

The nutrient composition of Khanna medium, in static condition revealed the best amylase production (Figure $1 \mathrm{~A})$, with about $38 \%$ more amylase yields than the SR medium, the second best composition of nutrients. This result was used in subsequent experiments, in which the fungus was incubated in Khanna medium, under stirring or static conditions, or in association of the two conditions, with a total time of incubation of $72 \mathrm{~h}$, initial $\mathrm{pH} 6.0$, at $40^{\circ} \mathrm{C}$ (Figure 1B). This experiment was carried out to verify if the changes in physical conditions of aeration during the growth would result in an increase in enzyme secretion. The highest amylolytic activity was once more observed with $72 \mathrm{~h}$ of incubation under static conditions

\section{Effect of initial pH on cultivation medium, time and temperature on the production of amylases}

The highest enzymatic production occurred in a culture medium with initial pH 6.5 (Figure 2). These results are similar to those reported for Aspergillus fumigatus (Goto et al., 1998), Aspergillus oryzae Ahlburg (Cohen) 1042.72 (Bennamoun et al., 2004) and Penicillium fellutanum (Kathiresan and Manivannan, 2006). The specific activity was higher with $72 \mathrm{~h}$ of growth (Figure 2B) and the maximum enzymatic activity was detected at $40^{\circ} \mathrm{C}$. At a higher temperature $\left(50^{\circ} \mathrm{C}\right)$, an accentuated decrease in enzymatic production to $25 \mathrm{U} / \mathrm{mg}$ protein was observed
(Figure 2C).

\section{Effect of different carbon sources on amylases production}

Among the tested carbon sources, milled corn, oatmeal, rice straw and soluble potato starch were the best inducers of enzymatic secretion (Figure 3). It was observed that milled corn and oatmeal together with soluble potato starch, which have high content of ions and vitamins, were important compounds for the growth of the microorganism. Other carbon sources tested such as rice straw, constituted basically of cellulose and hemicellulose, were not specific inducers of amylase. Maisena $^{\mathrm{TM}}$ (commercial product obtained from corn starch), maltose, wheat bran, amylopectin and raffinose also demonstrated an excellent induction of amylases. On the other hand, sugar cane bagasse, corn cob sucrose, lactose and arabinose were the worst inducers of amylase synthesis, showing amylolytic yields close to the filtrate obtained from cultures incubated without carbon sources.

\section{Different substrates hydrolysis}

A. niveus amylases $(3.6 \mathrm{U} / \mathrm{mg})$ were used to hydrolyze cassava flour, corn flakes, barley flakes, rye flakes, oat flakes, wheat bran and soy flakes (Figure 4). The highest reducing sugar liberation occurred when the enzymatic extract was incubated with cassava flour and the lower quantity was observed when the substrate was soy flakes. 

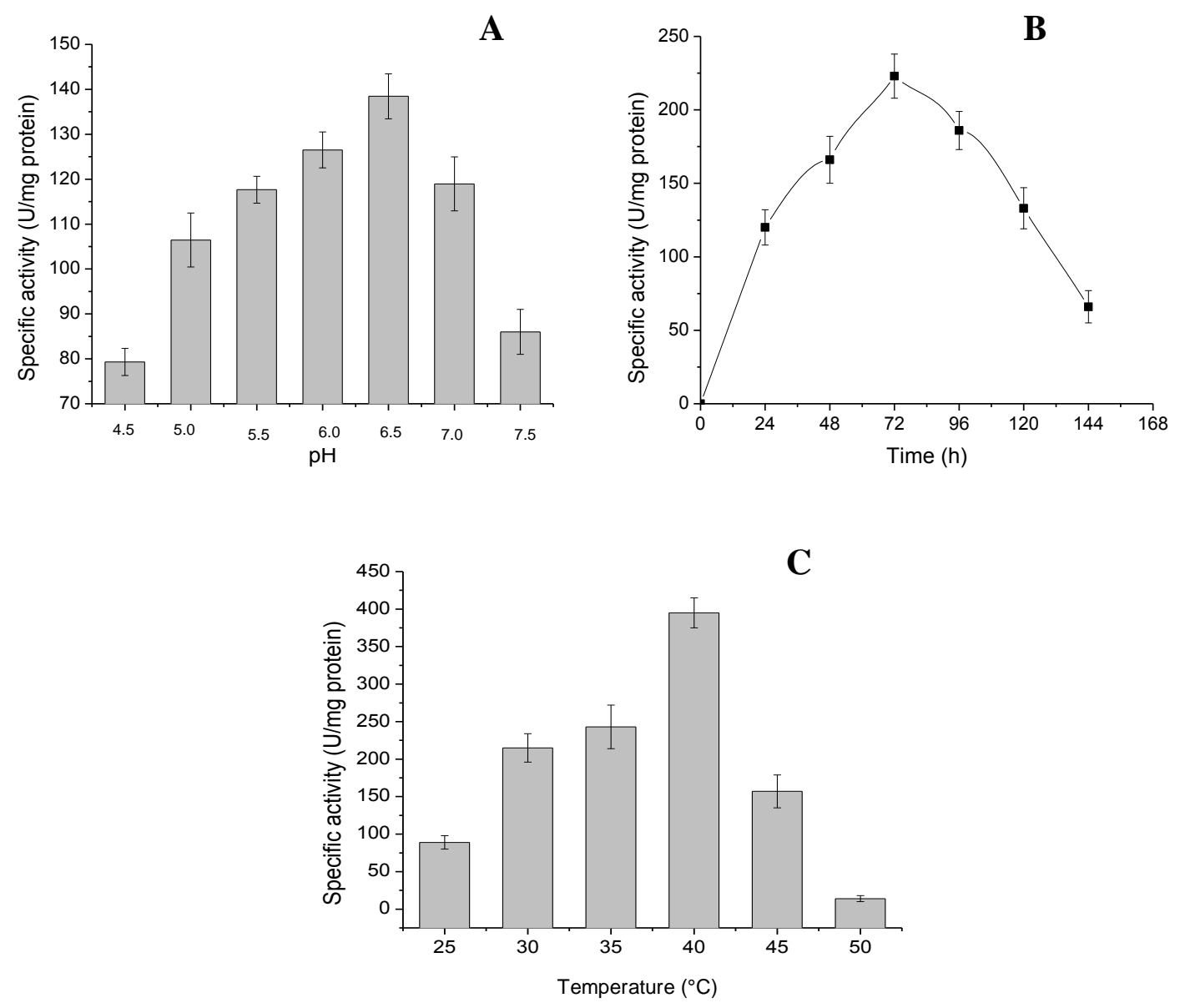

Figure 2. (A) Influence of $\mathrm{pH}$ on amylase production; $(\mathrm{B})$ time-course and $(\mathrm{C})$ temperature of incubation and amylase production by $A$. niveus.

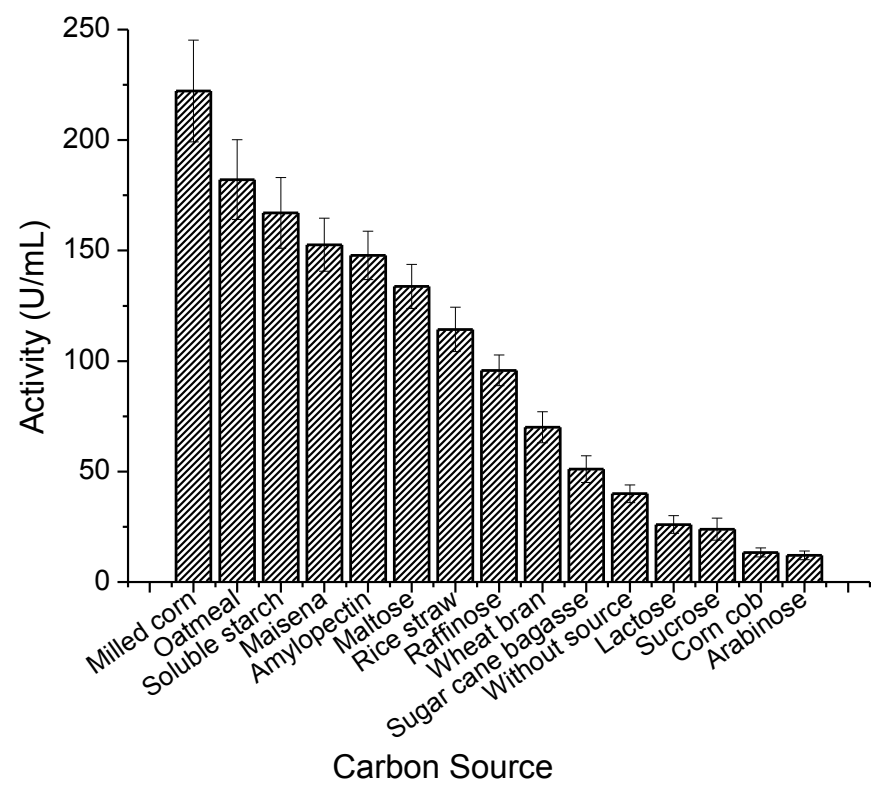

Figure 3. Effect of carbon sources on amylase production for $A$. niveus cultivated in medium Khanna, initial $\mathrm{pH} 6.5$, by $72 \mathrm{~h}$, at $40^{\circ} \mathrm{C}$. 


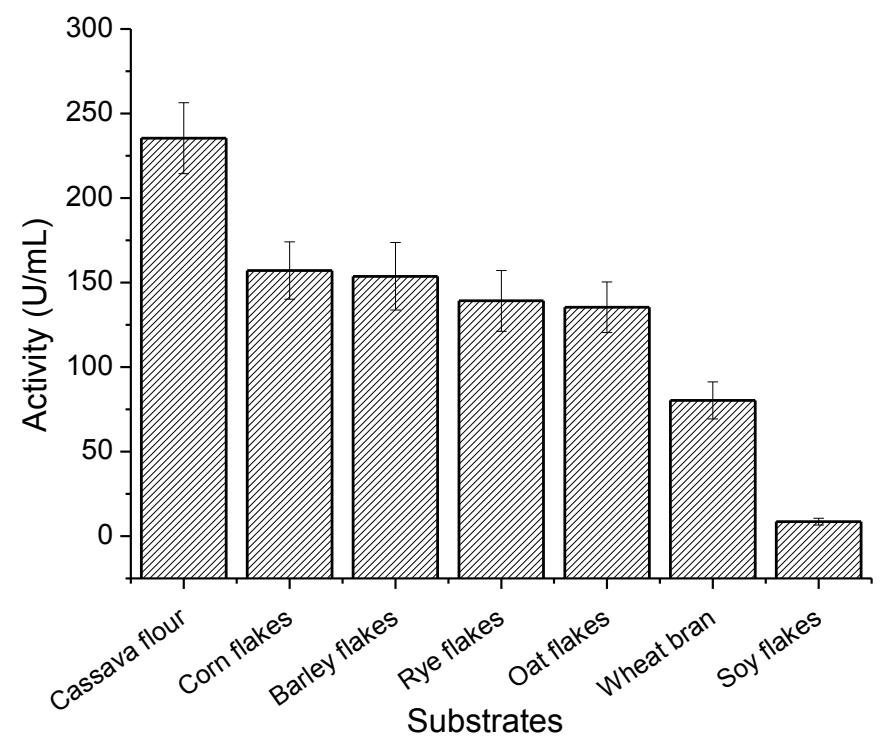

Figure 4. Hydrolysis of different substrates. A. niveus was cultivated in medium Khanna, initial $\mathrm{pH} 6.5$, by $72 \mathrm{~h}$, at $40^{\circ} \mathrm{C}$.

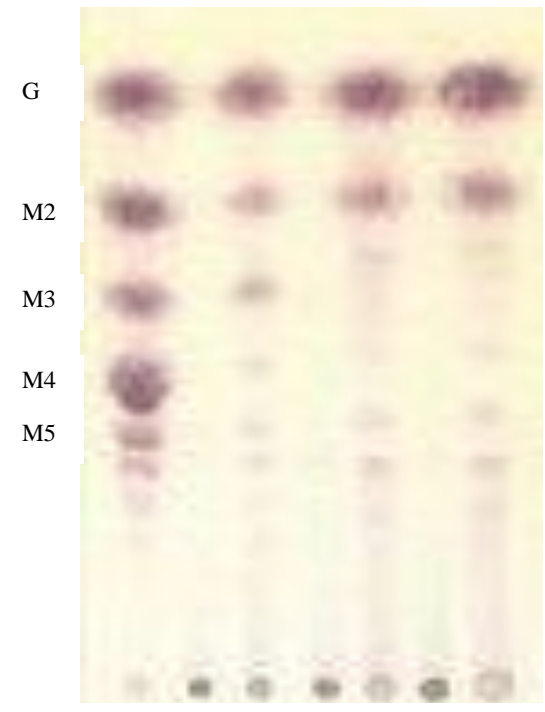

St MC M MSC MS RSC RS

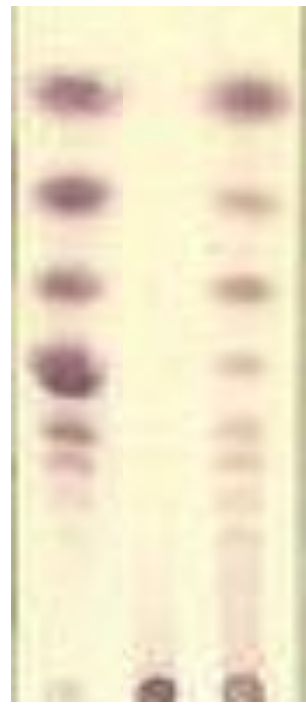

St $\quad$ SSC SS

Figure 5. Thin layer chromatography of the hydrolysis products of amylase obtained from culture media supplemented with different carbon sources. For enzymatic assay, $1.0 \%(\mathrm{w} / \mathrm{v})$ starch was used and the reaction occurred at $60^{\circ} \mathrm{C}$, for $2 \mathrm{~h}$. St, Standard (G, glucose; M2, maltose; M3, maltotriose; M4, maltotetraose; M5, maltopentaose); MC, maltose control; M, maltose; MSC, Maisena ${ }^{\text {TM }}$ control; MS $^{\text {TM }}$, Maisena; RSC, rice straw control; RS, rice straw; SSC, soluble starch control and SS, soluble starch. Controls correspond at time zero of assay.

\section{Hydrolysis products analysis}

A. niveus crude extract cultures obtained from media supplemented with soluble starch, rice straw, maisena ${ }^{\mathrm{TM}}$ or maltose, as carbon sources were assayed with commercial $1 \%$ starch. The reducing sugars formed during the hydrolysis were analyzed by thin layer chromatography (Figure 5). The higher diversity of maltooligosaccharides was formed when starch was the inducer, which revealed mono-, di-, tri- and traces of 

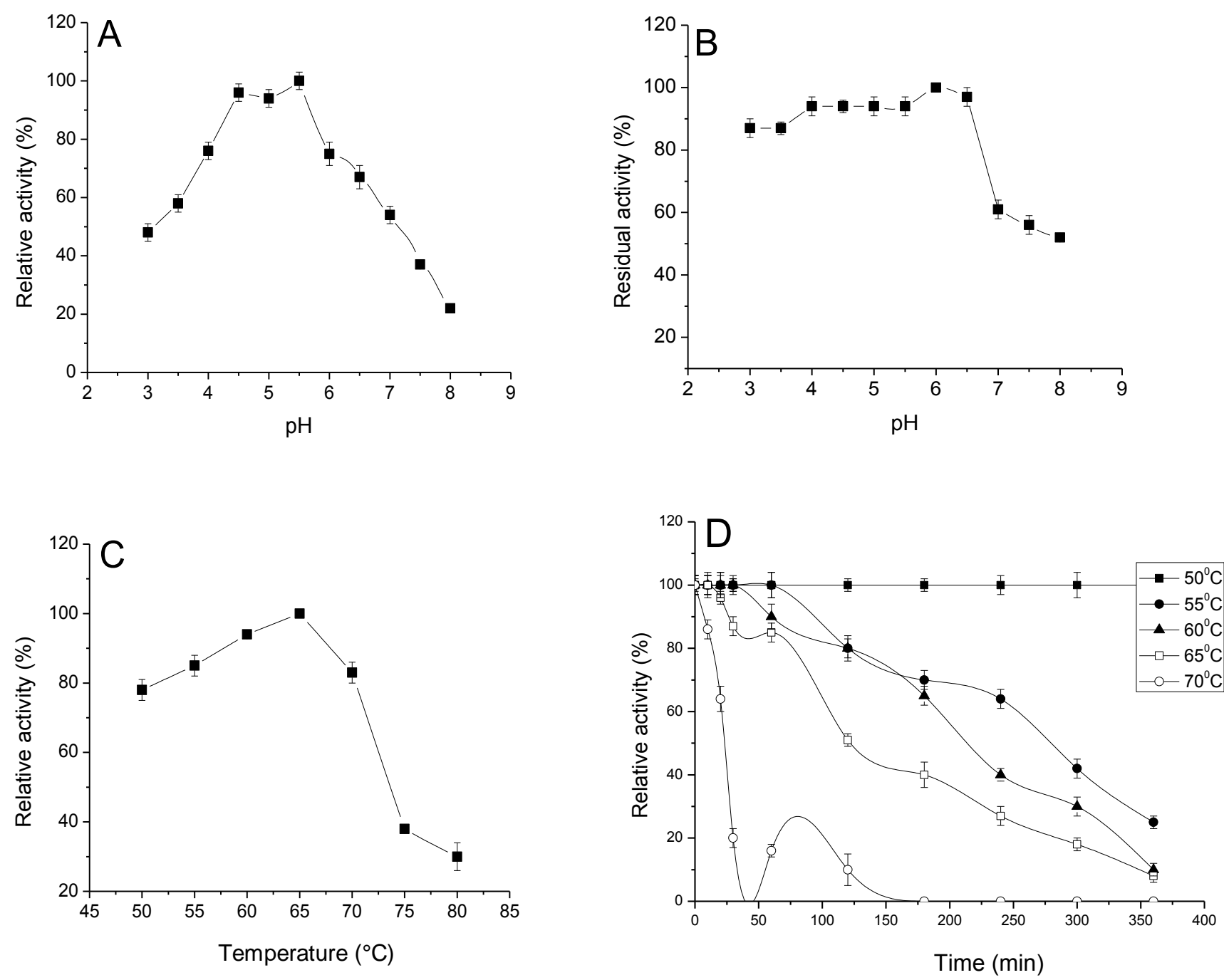

Figure 6. Influence of $\mathrm{pH}$ and temperature on amylolytic activity. $\mathrm{A}-\mathrm{pH}$ of the assay; $\mathrm{B}-$ amylase stability in different $\mathrm{pH}$; $\mathrm{C}$ temperature of assay and $\mathrm{D}$ - amylase thermostability at $50^{\circ} \mathrm{C}(\boldsymbol{\square}) ; 55^{\circ} \mathrm{C}(\bullet), 60^{\circ} \mathrm{C}(\mathbf{\Delta}), 65^{\circ} \mathrm{C}(\square)$ and $70^{\circ} \mathrm{C}(\mathrm{O})$.

oligosaccharides. On the other hand, when maltose was used as a carbon source, minor diversity of sugars was observed. Filtrates of cultures induced by Maisena ${ }^{\mathrm{TM}}$ and rice straw presented maltose and glucose as major hydrolysis products. The different profiles of the endproducts of the four inducers suggested that distinct enzymatic complexes could be be synthesized by $A$. niveus, or could it be the same enzymes produced in different expression levels. It is possible that the corresponding glucose bands were formed due to the hydrolytic action of glucoamylase, while the maltose and maltotriose corresponding bands were formed due to $\alpha$ amylase activity.

\section{Effects of temperature and $\mathrm{pH}$ on amylolytic activity}

The enzymatic assays were carried out at $\mathrm{pH} 3$ to 8.0 (Figure 6A). The higher activities were obtained at pH 4.5 and 5.5. This data suggested the presence of more than one enzyme with amylolytic activity in the crude extract, which can only be proved by the elution in chromatography columns. An $A$. terreus a-amylase presented a great activity at pH 5.0 (Ali and Hossain, 1991). On the other hand, an a-amylase of Cryptococcus flavus presented a great $\mathrm{pH}$ activity corresponding to 5.5 (Wanderley et al., 2004) and a-amylase of $A$. oryzae presented a $\mathrm{pH}$ reaction corresponding to 6.0 , close to the neutrality (Carlsen et al., 1996). Testing pH stability of $A$. niveus amylase (Figure $6 \mathrm{~B}$ ) showed the observation of a good performance in a wide range of $\mathrm{pH}$ (3.0 to 6.5) possible

In order to analyze the effect of temperature, $A$. niveus enzymatic assays were carried out at 50 to $80^{\circ} \mathrm{C}$ (Figure $6 \mathrm{C}$ ). The higher enzymatic levels were observed at $65^{\circ} \mathrm{C}$, which is considered greater than those determined for mesophilics linkages of $A$. terreus, $A$. terreus NA-170 and 
A
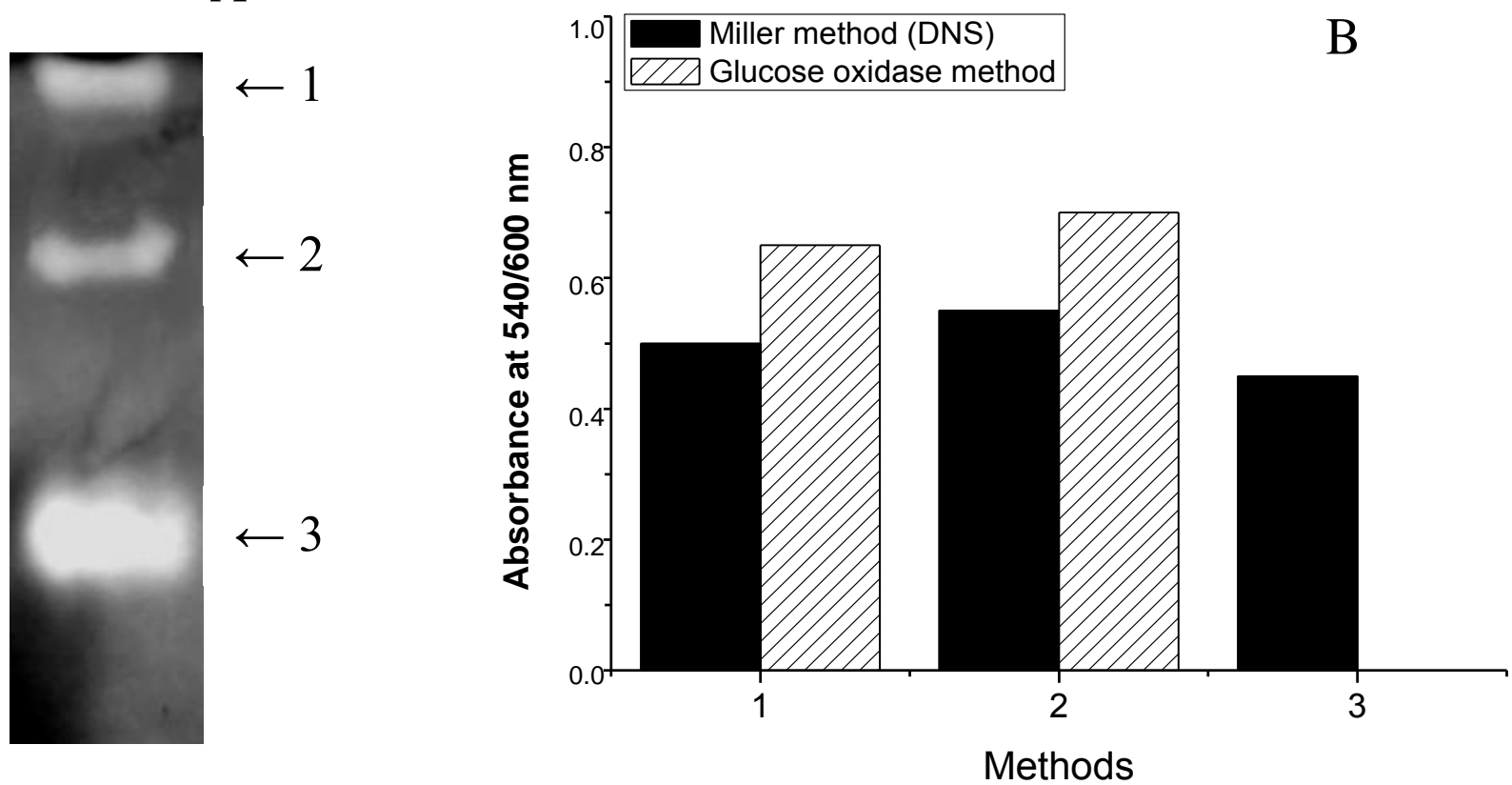

Figure 7. (A) Amylolytic activities in PAGE containing $1 \%$ starch. (B) Reducing sugar and glucose liberated from enzymatic action of bands 1,2 and 3 on $1 \%$ starch solution.

A. fumigatus (Nguyen et al., 2002; Ghosh et al., 1991; Silva and Peralta, 1998), respectively. The enzymes were stable for six hours at $50^{\circ} \mathrm{C}$. At $55^{\circ} \mathrm{C}, 50 \%$ of the initial activity was retained after four hours. These data are important for a possible application in industrial processes having in mind the long period of hydrolyzes using these enzymes in high or moderate temperatures.

\section{Amylolytic activity in polyacrylamide gel electrophoresis (PAGE)}

The crude extract containing amylolytic activity was applied in a non-denaturing polyacrylamide gel electrophoresis (PAGE) (Figure 7), and after running, it was revealed as described in the materials and methods section. It was possible to verify the presence of three bands with amylolytic activities revealed by $\mathrm{KI}$ and $\mathrm{I}_{2}$ solutions (Figure 7A), by measuring the loss of binding capacity between starch and iodine resulting from the action of amylases. In order to better define the type of enzyme corresponding to the bands with amylolytic activity, the gel was sliced and the final products was determined by DNS and GOD. It is possible to suggest that the bands 1 and 2 correspond to glucoamylase activity and band 3 corresponds to a-amylase activity, because glucose was not detected in this sample (Figure $7 \mathrm{~B})$. The ability of producing an enzymatic complex is usually common among filamentous fungi. This is interesting, because these enzymes might be used in association with different stages of starch saccharification.

\section{Conclusion}

The presence of three enzymes with amylolytic activity in gel electrophoresis revealed the presence of a complex amylolytic system that efficiently produces glucose, maltose and maltooligosacchacarides as hydrolysis product of starch. The physicochemical characteristics of these enzymes, as $\mathrm{pH}$ and temperature, on activity and stability at high temperatures demonstrated that these enzymes produced by a novel isolated thermotolerant filamentous fungus, Aspergillus niveus has a great potential to be industrially applied in the hydrolysis of starch.

\section{ACKNOWLEDGEMENTS}

This work was supported by grants from Fundação de Amparo à Pesquisa do Estado de São Paulo (FAPESP), Conselho de Desenvolvimento Científico e Tecnológico (CNPq) and National System for Research on Biodiversity (Sisbiota-Brazil, CNPq 563260/20106/FAPESP no 2010/52322-3). J.A.J. and M.L.T.M.P. are Research Fellows of CNPq. T.M.S. is recipient FAPESP Fellowship. We thank Ricardo Alarcon, Mariana Cereia and Mauricio de Oliveira for technical assistance. 


\section{REFERENCES}

Adams PR (1990). Mycelial amylase activities of thermophilic species of Rhizomucor, Humicola and Papulaspora. Mycopatologia 112:35-37.

Aiyer, PV (2005). Amylases and their applications. Afr. J. Biotechnol. 4(13):1525-1529.

Ali S, Hossain Z (1991). Characteristics for glucoamylase from Aspergillus terreus. J. Appl. Bacteriol. 71:144-146.

Aquino AC, Jorge AJ, Terenzi HF, ML Polizeli (2003). Studies on thermostable alpha-amylase from thermophilic fungus Scytalidium thermophilum. Appl. Microbiol. Biotechnol. 61:323-328.

Baks T, Janssen AEM, Boom RM (2006). The effect of carbohydrates on $\alpha$-amylase activity measurements. Enzyme Microb. Technol. 39:114-119.

Bennamoun L, Meraihi Z, dakhmouche S (2004). Utilisation de la planification expérimentale pour 1'optimisation de la production de 1' $\alpha$-amylase par Aspergillus oryzae Ahlburg (Cohen) 1042.72 cultivé sur milieu à base de déchets d'oranges. J. Food Eng. 64:257-264.

Betini, JHA, Michelin M, Peixoto-Nogueira SC., Jorge JA, Terenzi HF, Polizeli MLTM (2009). Xylanases from Aspergillus niger, Aspergillus niveus and Aspergillus ochraceus produced under solid-state fermentation and their application in cellulose pulp bleaching. Bioprocess Biosyst. Eng. 32:819-824.

Bhanja T, Rout S, Banerjee R, Bhattacharyya BC (2007). Comparative profiles of $\alpha$-amylase production in conventional tray reactor and GROWTEK bioreactor. Bioprocess Biosyst. Eng. 30:369-376.

Carlsen M, Sphor AB, Nielsen J, Villadesn J (1996). Morphology and physiology of an a-amylase producing strain of Aspergillus oryzae during batch cultivation. Biotechnol. Bioeng. 4:266-276.

Cereia M., Guimarães LHS, Peixoto-Nogueira SC, Jorge JA, Terenzi HF, Greene LJ, Polizeli MLTM. (2006). Glucoamylase isoform (GA II) purified from a thermophilic fungus Scytalidium thermophilum 15.8 with biotechnological potential. Afr. J. Biotechnol. 5:1239-1245.

Ghosh A, Chatterjee B, Das A (1991). Purification and characterization of glucoamylases of Aspergillus terreus NA-170 mutant. J. Appl. Bacteriol. 71:162-169.

Goto CE, Barbosa EP, Kistner LCL, Ganda RF, Arrias VL, Peralta RM (1998). Production of amylases by Aspergillus fumigatus. Rev. Microbiol. 29:99-103.

Gupta R, Gigras P, Mohapatra H, Kuma VG, Chauhan B (2003). Microbiol $\alpha$-amylases: a biotecnological perspective. Process Biochem. 38:1599-1616.

Imai Y, Sukura M, Masamoto M, Nagayasu K (1994). Glucoamylase production of Aspergillus oryzae in fed-batch culture using a statistical regression model. J. Ferment. Bioeng. 78:310-314.

Kathiresan K, Manivannan S (2006). a-Amylase production by Penicillium fellutanum isolated from mangrove rhizosphere soil. Afr. J. Biotechnol. 5:829-832.
Khanna P, Sundari SS, Kumar NJ (1995). Production, isolation and partial purification of xylanase from Aspergillus sp. World J. Microbiol. Biotechnol. 11:242-243.

Maller A, Damásio ARL, Silva TM, Jorge, JA, Terenzi HF, Polizeli MLTM (2011). Biotechnological potential of agro-industrial wastes as carbon source to thermostable polygalacturonase production in Aspergillus niveus. Enzyme Res. pp. 1-6.

Nguyen QD, Rezessy-szabó JM, Claeyssens M, Stals I, Hoschke A (2002). Purification and characterization of amylolytic enzymes from thermophilic fungus Thermomyces lanuginosus strain ATCC 34626. Enzyme Microb. Technol. 31:345-352.

Peixoto SC, Jorge JA, Terenzi HF, Polizeli MLTM (2003). Rhizopus microsporus var. rhizopodiformis: a thermotolerant fungus with potential for production of thermostable amylases. Int. Microbiol. 6:269-273.

Peixoto-Nogueira SC, Michelin M, Betini JHA, Jorge JA, Terenzi HF, Polizeli MLTM (2008). Production of xylanase by Aspergilli using alternative carbon sources: application of the crude extract on cellulose pulp biobleaching. J. Ind. Microbiol. Biotechnol. 36:149-155.

Reddy NS, Nimmagadda A, Rao KRSS (2003). An overview of the microbial a-amylase family. Afr. J. Biotechnol. 2(12):645-648.

Rizzatti ACS, Jorge JA, Terenzi HF, Rechia CGV, Polizeli MLTM (2001). Purification and properties of a thermostable extracellular $\beta$ D-xylosidase produced by thermotolerant Aspergillus phoenicis. J. Ind. Microbiol. Biotechnol. 26:156-160.

Salahuddin K, Prasad R, Kumar S, Visavadia MD (2011). Isolation of soil thermophilic strains of actinomycetes for the production of $\alpha$ amylase. Afr. J. Biotechnol. 10 (77):17831-17836.

Silva TM, Almeida FBR, Damásio ARL, Maller A, Michelin M, Jorge JA Hanna ES, Roque-Barreira MC, Terenzi HF, Polizeli MLTM (2010). Tunicamycin inhibition of $\mathrm{N}$-glycosylation of a-glucosidase from Aspergillus niveus: partial influence on biochemical properties. Biotechnol. Lett. 32:1449-1455.

Silva WB, RM Peralta (1998). Purification and characterization of a thermostable glucoamilase from $A$. fumigatus. Can. J. Microbiol. 44:493-497.

Sukara E, Doelle HW (1989). A one-step process for the production of single cell protein and amyloglucosidase. Appl. Microbiol. Biotechnol. 30:135-140.

Wanderley JK, Torres GAF, Moraes PML, Ulhoa JC (2004). Biochemical characterization of $\alpha$-amylase from the yeast Cryptococcus flavus. FEMS Microbiol. 231:165-169.

Wiseman A (1975). Handbook of Enzyme Biotechnology. Ltd John Wiley \& Sons, editors pp. 148. 